\title{
Effect of phosphoric acid etching on the shear bond strength of two self-etch adhesives
}

\author{
Camila SABATINI ${ }^{1}$ \\ 1- DDS, MS, Assistant Professor, SUNY at Buffalo, School of Dental Medicine Department of Restorative Dentistry, Buffalo, NY, USA.
}

Corresponding address: Camila Sabatini - School of Dental Medicine - Department of Restorative Dentistry - 3435 - Main Street, 215 - Squire Hall - Buffalo, NY 14214 - USA - Phone: +1 (716) 829-6343 - Fax: +1 (716) 829-2440 - e-mail: cs252@buffalo.edu

Received: May 9, 2012- Modification: January 03, 2013 - Accepted: January 11, 2013

\section{ABSTRACT}

\begin{abstract}
O bjective: To evaluate the effect of optional phosphoric acid etching on the shear bond strength (SBS) of two self-etch adhesives to enamel and dentin. Material and Methods: Ninety-six bovine mandibular incisors were ground flat to obtain enamel and dentin substrates. A two-step self-etch adhesive (FL-Bond II) and a one-step self-etch adhesive (BeautiBond) were applied with and without a preliminary acid etching to both the enamel and dentin. The specimens were equally and randomly assigned to 4 groups per substrate $(\mathrm{n}=12)$ as follows: FL-Bond II etched; FL-Bond II un-etched; BeautiBond etched; BeautiBond un-etched. Composite cylinders (Filtek Z100) were bonded onto the treated tooth structure. The shear bond strength was evaluated after 24 hours of storage $\left(37^{\circ} \mathrm{C}\right.$, $100 \%$ humidity) with a testing machine (Ultra-tester) at a speed of $1 \mathrm{~mm} / \mathrm{min}$. The data was analyzed using a two-way ANOVA and post-hoc Tukey's test with a significance level of $p<0.05$. A field emission scanning electron microscope was used for the failure mode analysis. Results: Both adhesives evidenced a significant decrease in the dentin SBS with the use of an optional phosphoric acid-etching step $(p<0.05)$. Preliminary phosphoric acid etching yielded significantly higher enamel SBS for FL-Bond II $(p<0.05)$ only, but not for BeautiBond. FL-Bond II applied to un-etched dentin demonstrated the highest mean bond strength (37.7 $\pm 3.2 \mathrm{MPa})$ and BeautiBond applied to etched dentin showed the lowest mean bond strength $(18.3 \pm 6.7 \mathrm{MPa})$ among all tested groups $(p<0.05)$. Conclusion: The use of a preliminary acid-etching step with $37.5 \%$ phosphoric acid had a significant adverse effect on the dentin bond strength of the self-etch adhesives evaluated while providing improvement on the enamel bond strength only for FL-Bond II. This suggests that the potential benefit that may be derived from an additional etching step with phosphoric acid does not justify the risk of adversely affecting the bond strength to dentin.
\end{abstract}

Key words: Shear strength. Dentin-bonding agents. Acid etching.

\section{INTRODUCTION}

The current self-etching approach of dental adhesives is based on the use of acidic resin monomers that allow simultaneous de-mineralization and infiltration of the partially desmineralized substrate with resin monomers. The simplified selfetch technique yields a resin-infiltrated zone that co-exists with minerals after only partial dissolution of hydroxyapatite ${ }^{17}$. Theoretically, an equivalent depth of desmineralization and monomer infiltration can be obtained with these systems, ${ }^{3}$ minimizing nano-leakage at the dentin-resin interface ${ }^{20}$. In addition, fewer procedural steps and overall less technique sensitivity offer significant advantages to the clinician ${ }^{22}$.

Self-etching systems are composed of aqueous mixtures of acidic functional monomers, generally phosphoric acid esters with a $\mathrm{pH}$ higher than phosphoric acid ${ }^{27}$. They can be classified as mild, intermediate or strong, based on their acidity ${ }^{16}$. Strong self-etch adhesives have a $\mathrm{pH}$ of around 1 , yielding ultra-morphological characteristics and etching patterns similar to those obtained with etch-and-rinse adhesives ${ }^{4}$. Conversely, mild self-etch systems have a $\mathrm{pH}$ of around 2 and yield only superficial desmineralization normally no greater than $1 \mu \mathrm{m}^{4}$. Despite the less aggressive 
etching pattern and shallower resin tag formation, sufficient micro-mechanical interlocking and good bond strengths may be obtained with mild self-etch systems. This may be the combined result of the simultaneous desmineralization and resin monomer infiltration ${ }^{4,10,11}$, and the remnant hydroxyapatite left attached to the collagen, which may serve as receptor for additional chemical adhesion ${ }^{32,33}$.

Despite the advantages associated with the use of self-etch adhesives, they still exhibit a number of shortcomings. Their acidic functional monomers create highly hydrophilic interfacial structures making them more susceptible to water sorption and hydrolytic degradation ${ }^{24}$. Particularly, the "allin-one adhesives", which combine a self-etching primer and a hydrophobic resin into a single application, yielding highly hydrophilic polymers that are much more permeable to water movement after polymerization ${ }^{24}$.

The shallower etching pattern and reduced micro-mechanical retention has been reported to be a concern with mild self-etch adhesives ${ }^{16,25,32}$, especially when bonding to unprepared enamel ${ }^{16,18}$ perhaps jeopardizing the strength of the resinenamel interface. Studies have also shown that bonding to ground versus unprepared enamel yields similar bond strengths of self-etching adhesives ${ }^{8}$. Since the evidence in the subject remains controversial, manufacturers often recommend a preliminary phosphoric acid etching step prior to the application of mild self-etch adhesives to improve the bond strength to enamel ${ }^{6,12,29}$. Good bond strengths to dentin have been shown with selfetch adhesives ${ }^{2,13}$; and thus, the use of preliminary phosphoric acid etching has not been advocated. The benefits of selective enamel etching prior to the application of mild self-etch adhesives have been well documented in the literature for both one-step ${ }^{5,21}$ and two-step ${ }^{5,28,29}$ self-etch adhesives. However, limiting the application of phosphoric acid to only enamel, is virtually impossible with the concern that dentin bond strength may be adversely affected if the etchant inadvertently reaches the dentin $^{9,29}$. Hence, gaining a better understanding of the effect of phosphoric acid etching on smear layercovered dentin is critical. Studies have shown a decreased bond strength to dentin when phosphoric acid was used prior to the application of two-step mild self-etch adhesives $5,7,28,29$. There is controversy as to the use of phosphoric acid etching in conjunction with one-step self-etch adhesives, with studies showing an improved bond strength ${ }^{21}$, no effect ${ }^{5}$ or reduced bond strength ${ }^{9}$ when phosphoric acid-etched dentin was subsequently treated with all-in-one adhesives. Most of these studies report on a single generation of adhesives or adhesives with different monomeric compositions. Self-etch adhesive formulations (FL-Bond II and BeautiBond,
Shofu, Kyoto, Japan) include a combination of carboxylic and phosphonic acid monomers as dentin and enamel adhesion promoters respectively. The combination of the two monomers is expected to provide similar bond strength to both enamel and dentin.

Since the bonding performance of self-etch adhesives is dependent on both adhesive generation and functional monomer composition, studies are required to evaluate different types of adhesives with similar monomeric composition. The present study aimed to evaluate the effect of an optional etching step with $37.5 \%$ phosphoric acid on the shear bond strength (SBS) of a one-step and twostep self-etch adhesive to enamel and dentin. The null hypothesis was that there would be no effect of the phosphoric acid etching on the shear bond strength to enamel and dentin. A second null hypothesis was that there would be no effect of the adhesive generation on the bond strength to enamel and dentin.

\section{MATERIAL AND METHODS}

Ninety-six freshly extracted, non-carious bovine mandibular incisors were used to obtain enamel and dentin substrates for bonding. The study was conducted under the Institutional Animal Care and Use Committee (IACUC) Approval number SIS07049N. The crowns were separated from the roots with a circular band saw (Isomet, Buehler, Lake Bluff, IL, USA) and embedded in a chemically polymerized methacrylate (Fastray, HJ Bosworth, Skokie, IL, USA) with the facial surface exposed. The facial surface was ground flat on a model trimmer to reveal either superficial enamel $(n=48)$ or superficial dentin $(n=48)$. The specimens were finished with 320-,400- and 600- grit silicon carbide abrasive paper (BuehlerMet Abrasive Papers, Buehler, Lake Bluff, IL, USA) and stored in deionized water at $4^{\circ} \mathrm{C}$ for less than one month until ready to be bonded. One hour prior to bonding, the specimens were acclimatized to room temperature $\left(23 \pm 2^{\circ} \mathrm{C}\right)$ and re-finished with 600 -grit abrasive paper to expose a fresh surface for bonding. A two-step self-etch adhesive FL-Bond II and a onestep self-etch adhesive BeautiBond were evaluated. The composition and application procedures for each of these adhesives, as per manufacturer's recommendations, are summarized in Table 1 . The specimens were equally and randomly assigned to four groups per substrate $(n=12)$ for evaluation of the variables adhesive generation (two-step self-etch vs. one-step self-etch) and conditioning technique (etch vs. non-etch) as follows: FL-Bond II etched; FL-Bond II un-etched; BeautiBond etched; BeautiBond un-etched.

The adhesives were applied following the 
manufacturer's instructions with or without preliminary etching treatment with $37.5 \%$ phosphoric acid (Ultra-etch, Ultradent, South Jordan, UT, USA). The groups treated with phosphoric acid were etched for 15 seconds, rinsed and air-dried prior to the application of the adhesives as per the steps outlined in Table 1 . The enamel was thoroughly air-dried, while the dentin was gently air-dried. An LED light curing unit (Bluephase 16i, Ivoclar-Vivadent, Amherst, NY, USA) was used, ensuring a minimum power density of $800 \mathrm{~mW} / \mathrm{cm}^{2}$ at all times by periodic monitoring with a radiometer (Demetron, Kerr, Orange, CA, USA). Immediately after polymerization of the adhesive, the specimens were placed on a specially fabricated jig (Ultradent, South Jordan, UT, USA) with a cylindrical mold (2.38 $\mathrm{mm}$ in diameter and $2.00 \mathrm{~mm}$ in height), which was filled with composite resin (Filtek Z100, 3M ESPE, Saint Paul, MN, USA), shade A2 in a single 2.00 $\mathrm{mm}$-increment and polymerized for 40 seconds. The specimens were stored in an incubator $\left(37^{\circ} \mathrm{C}\right.$, $100 \%$ humidity) and the shear bond strength was evaluated after $24 \mathrm{~h}$ with a calibrated testing device (Ultratester, Ultradent, South Jordan, UT, USA) loaded at a crosshead test speed of $1 \mathrm{~mm} / \mathrm{min}$ and a load cell of $1,000 \mathrm{lbs}$. (453.6 g). A notched crosshead designed to match the diameter of the bonded cylinder was used to apply the testing load. The load required to de-bond the specimen was recorded and expressed in megapascals (MPa) and the descriptive statistics were determined.

Two separate two-way analysis of variance tests (ANOVA) were conducted for enamel and dentin substrates with the main variables adhesive generation (two-step self-etch vs. one-step selfetch) and conditioning technique (etch vs. nonetch). The post-hoc multiple comparisons Tukey's test was used for pairwise comparisons between the group means. A significance level of $p<0.05$ was used for all tests. All statistical analysis was performed with Statistical Package for Social Sciences (SPSS) version 16.0 (SPSS Inc, Chicago, IL, USA). The analysis of the failure mode was conducted through observations by a single trained evaluator, with a field emission scanning electron microscope (FE-SEM), using a secondary electron and back-scattered detector (Hitachi SU-70, Hitachi, Krefeld, Germany) at 50x magnification. The failed interfaces were classified as adhesive, cohesive in enamel or dentin, cohesive in composite, or mixed ${ }^{21}$.

\section{RESULTS}

Both adhesive generation and conditioning technique demonstrated a significant effect on the shear bond strength to enamel $(p=0.02$ and $p=0.02$ respectively) and dentin $(p<0.001$ and $p<0.001$, respectively). For both enamel and dentin, the interactions between the variables adhesive generation and conditioning technique were shown to be not significant.

The mean shear bond strength and failure mode distribution for the two adhesives evaluated to enamel and dentin substrates are summarized in Table 2 and 3 respectively. Although both adhesives demonstrated increased bond strengths to enamel when applied followed treatment with phosphoric acid, significant differences were detected only for FL-Bond II $(p<0.05)$. Following phosphoric acid etching, the mean bond strengths for FL-Bond II increased approximately by $15 \%$, from $28.3 \pm 6.3$ to $33.3 \pm 2.7$, and those for BeautiBond increased approximately by $7 \%$, from $26.4 \pm 6.8$ to $28.4 \pm 3.4$. When dentin was etched with phosphoric acid, both adhesives resulted in significantly decreased bond strength $(p<0.05)$. The mean bond strength

Table 1- Study materials, composition and application protocol as per manufacturer description

\begin{tabular}{|c|c|c|c|c|}
\hline $\begin{array}{c}\text { Adhesive } \\
\text { (manufacturer) }\end{array}$ & $\mathrm{pH}$ & Batch No. & Composition & Application Protocol \\
\hline $\begin{array}{c}\text { FL-Bond II } \\
\text { (Shofu, Kyoto, Japan) } \\
\text { Two-step self-etch }\end{array}$ & 2.4 & 309 & $\begin{array}{c}\text { Primer: Water, ethanol, carboxylic } \\
\text { acid monomer, phosphoric acid } \\
\text { monomer \& initiator } \\
\text { Adhesive: S-PRG based on } \\
\text { fluoroboroaluminosilicate glass, } \\
\text { UDMA, TEGDMA, 2-HEMA, initiator }\end{array}$ & $\begin{array}{l}\text { Apply primer, leave undisturbed for } \\
\qquad 10 \mathrm{~s} \text {, air dry } \\
\text { Apply bonding agent, do not air dry } \\
\text { Polymerize for } 5 \mathrm{~s} \text { with LED }\end{array}$ \\
\hline $\begin{array}{c}\text { BeautiBond } \\
\text { (Shofu, Kyoto, Japan) } \\
\text { One-step self-etch }\end{array}$ & 2.4 & 20936 & $\begin{array}{l}\text { Bis-GMA,TEGDMA, phosphonic } \\
\text { acid monomer, carboxylic acid } \\
\text { monomer, acetone, water }\end{array}$ & $\begin{array}{c}\text { Apply adhesive, leave undisturbed } \\
\text { for } 10 \mathrm{~s} \\
\text { Strong air dry for } 3 \mathrm{~s} \\
\text { Polymerize for } 5 \mathrm{~s} \text { with LED }\end{array}$ \\
\hline
\end{tabular}

S-PRG, silica pre-reacted glass; UDMA, di(methacryloxyethyl)trimethylhexamethylene diurethane; TEGDMA, triethylene glycol dimethacrylate; 2-HEMA, 2-hydroxyethyl methacrylate; Bis-GMA, 2,2bis[4-(2-hydrogen-3-methacryloyloxypropoxy) phenyl]propane. 
values for FL-Bond II decreased approximately by $26 \%$, from $37.7 \pm 3.2$ to $28.0 \pm 8.5$, and those for BeautiBond decreased approximately by $34 \%$, from $27.8 \pm 8.0$ to $18.3 \pm 6.7$.

For both enamel and dentin, whether the adhesives were applied following phosphoric acid treatment or according to the manufacturer's instructions without phosphoric acid etching, the mean bond strength values were significantly higher for FL-Bond II than BeautiBond $(p<0.05)$ for all groups except when bonding to un-etched enamel. FL-Bond II applied to un-etched dentin demonstrated the highest mean bond strength (37.7 $\pm 3.2 \mathrm{MPa})$ and BeautiBond applied to etched dentin showed the lowest mean bond strength $(18.3 \pm 6.7 \mathrm{MPa})$ among all tested groups $(p<0.05)$.

Failure mode distribution of the specimens bonded to enamel and dentin are also provided in

Table 2- Mean shear bond strength results and failure mode distribution for both adhesives applied to phosphoric acidetched vs. non-etched enamel substrates $(n=48)$. Modes of failure described as adhesive $(A)$, cohesive in enamel $(C E)$, cohesive in composite (CC), and mixed (M)

\begin{tabular}{ccccc}
\hline & \multicolumn{2}{c}{ Enamel etched } & \multicolumn{2}{c}{ Enamel non-etched } \\
& SBS & Failure mode & SBS & Failure mode \\
& Mean \pm SD & A/CE/CC/M & Mean \pm SD & A/CE/CC/M \\
\hline FL-Bond II & $33.3^{2} \pm 2.7^{\mathrm{a}, \mathrm{A}}$ & $0 / 0 / 2 / 10$ & $28.3^{\mathrm{a}} \pm 6.3^{\mathrm{b}, \mathrm{A}}$ & $0 / 1 / 2 / 9$ \\
BeautiBond & $28.4 \pm 3.4^{\mathrm{a}, \mathrm{B}}$ & $2 / 1 / 2 / 7$ & $26.4 \pm 6.8^{\mathrm{a}, \mathrm{A}}$ & $5 / 1 / 2 / 4$ \\
\hline
\end{tabular}

Same superscript letter indicates no significant differences between groups as per the results of pairwise multiple comparisons Tukey's test $(p<0.05)$. Lower case denotes differences between etched and non-etched groups within each adhesive (horizontal). Upper case denotes differences between adhesive generations within each conditioning treatment (vertical).

Table 3- Mean shear bond strength results and failure mode distribution for both adhesives applied to phosphoric acidetched vs. non-etched dentin substrates $(n=48)$. Modes of failure described as adhesive $(A)$, cohesive in dentin $(C D)$, cohesive in composite (CC), and mixed (M)

\begin{tabular}{ccccc}
\hline & \multicolumn{2}{c}{ Dentin etched } & \multicolumn{2}{c}{ Dentin non-etched } \\
& SBS & Failure mode & SBS & Failure mode \\
& Mean \pm SD & A/CD/CC/M & Mean \pm SD & A/CD/CC/M \\
\hline FL-Bond II & $28.0 \pm 8.5^{\mathrm{a}, \mathrm{A}}$ & $6 / 0 / 1 / 5$ & $37.7 \pm 3.2^{\mathrm{b}, \mathrm{A}}$ & $0 / 0 / 0 / 12$ \\
BeautiBond & $18.3 \pm 6.7^{\mathrm{a}, \mathrm{B}}$ & $12 / 0 / 0 / 0$ & $27.8 \pm 8.0^{\mathrm{b}, \mathrm{B}}$ & $6 / 0 / 0 / 6$ \\
\hline
\end{tabular}

Same superscript letter indicates no significant differences between groups as per the results of pairwise multiple comparisons Tukey's test $(p<0.05)$. Lower case denotes differences between etched and non-etched groups within each adhesive (horizontal). Upper case denotes differences between adhesive generations within each conditioning treatment (vertical).

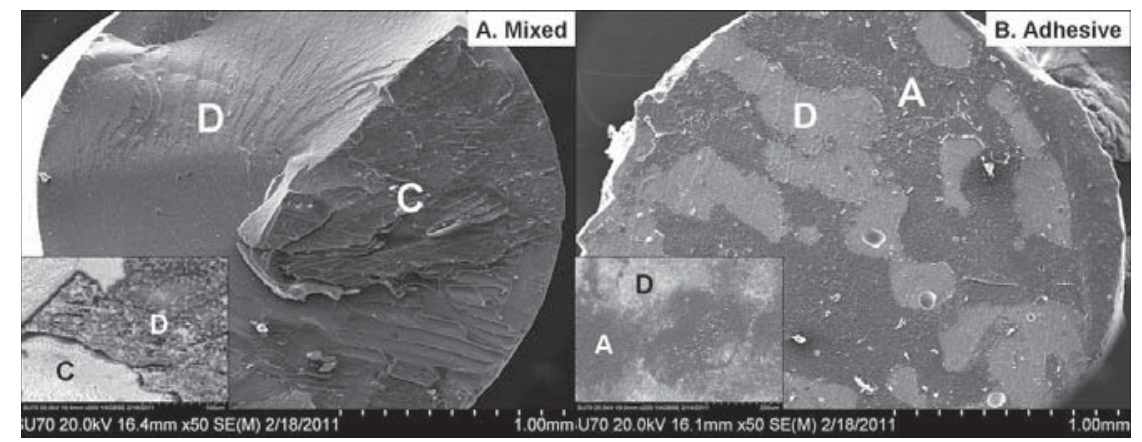

Figure 1- FE-scanning-electron microscopy (SEM) images in secondary electron and back-scattered electron mode of the fractured interface for representative failure modes. 1.A. Mixed failure: towards the right, large cohesive failure in composite resin (C); towards the left, cohesive failure in dentin (D). Greater magnification of the same image shows area where the fracture transitions from cohesive failure in composite to cohesive failure in dentin across the different interfacial layers. 1.B. Adhesive failure: spotted areas of adhesive-coated dentin (A) and dentin (D) 
Tables 2 and 3. Overall, adhesive and mixed failures were the most prevalent types of failure. Higher bond strength values were generally associated with mixed failures and lower bond strength values with adhesive failures. BeautiBond bonded to etched dentin revealed $100 \%$ adhesive failures and the lowest bond strength of all groups (18.3 $\pm 6.7 \mathrm{MPa})$, whereas FL-Bond II bonded to un-etched dentin demonstrated $100 \%$ mixed failures and the highest

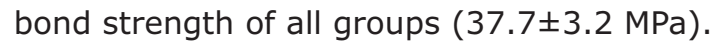

\section{DISCUSSION}

The present study evaluated the effect of an optional etching step with $37.5 \%$ phosphoric acid on the shear bond strength of a one-step and twostep self-etch adhesive to enamel and dentin. Both null hypotheses were rejected since the conditioning technique and adhesive generation were both shown to have a significant effect on the bond strength to the enamel and dentin.

Similar to the results from previous studies, which have demonstrated the beneficial effects of enamel etching with phosphoric acid5,21,28,29, our results also found significantly improved enamel bond strengths for surfaces etched with phosphoric acid for the two-step adhesive FL-Bond II, but not for the all-in-one adhesive BeautiBond. The nature of enamel bonds being primarily micro-mechanical ${ }^{14,21}$ provides at least a partial explanation for the enhanced bond strengths observed for FL-Bond II to etched enamel. Nevertheless, the bond strength values to the un-etched enamel, in the range of 26$28 \mathrm{MPa}$, suggest that the acidity of the monomers present in the adhesives tested may have sufficient strength to achieve intimate micro-mechanical retention.

A significant adverse effect was demonstrated when dentin was etched with $37.5 \%$ phosphoric acid prior to the application of both self-etch adhesives. This result is in agreement with previous studies, which have demonstrated decreased dentin bond strengths when phosphoric acid etching was used prior to the application of one-step ${ }^{5,9}$ and two-step ${ }^{5,7,28,29}$ self-etch adhesives. Among other aspects, the negative effect of phosphoric acid in dentin may be the combined result of over-etching, sub-optimal removal of the phosphoric acid; incomplete adhesive infiltration into the denuded collagen network ${ }^{15,28}$; and removal of residual hydroxyapatite from the collagen mesh, which could compromise the potential for chemical adhesion ${ }^{32,33}$. The adverse effects of phosphoric acid treatment on dentin bond strength were more pronounced for the single step adhesive BeautiBond than for the self-etching primer FL-Bond II, which showed a decrease in bond strength of approximately 34\% and $26 \%$ respectively. This result may suggest that
BeautiBond may be more dependent on residual hydroxyapatite than FL-Bond II or other alterations of the etched dentin structure.

In general, the effect of additional demineralization with phosphoric acid is expected to be dependent on aspects such as functional monomer composition and adhesive generation, since the properties and interactions taking place in adhesive interfaces created differently are also expected to vary ${ }^{30}$. However, since there is a high productdependency aspect associated with the interactions taking place between the functional monomers and dental substrate, no definitive statements can be made as to effect of additional phosphoric acid etching on the dentin bond strength of different adhesive compositions. Most available studies have evaluated adhesives corresponding to a single class or generation. Only one study was identified that included both a two-step and one-step self-etch adhesive $^{5}$; however, the adhesives tested were from different manufacturers and possessed different monomeric compositions. The more hydrophilic nature of all-in-one adhesives creates weaker, unstable hybrid layers that are more susceptible to hydrolytic degradation and proteolysis ${ }^{26}$. Moreover, the greater hydrophilicity of all-in-one adhesives has been reported to compromise their bonding ability, particularly to inherently hydrophilic dentin by preventing complete polymerization of the acidic monomers within the hybrid layer ${ }^{31}$. Due to their inherent hydrophilicity, it is thus likely that additional dissolution of the smear layer following acid etching may be more detrimental to interfaces created by all-in-one adhesives than those created by self-etching primers ${ }^{23}$.

With exception of all-in-one BeautiBond bonded to etched dentin, which showed a mean bond strength value of $18.3 \mathrm{MPa}$, bond strengths ranging from 26 to $37 \mathrm{MPa}$ were demonstrated irrespective of phosphoric acid treatment. This result indicates that despite the less aggressive etching pattern obtained with self-etch adhesives, enough micromechanical interlocking through hybridization and strong bonds can still be obtained through the combined mechanical and chemical adhesion of selfetch adhesives with the dental hard tissues ${ }^{4,10,11}$. These results suggest that the potential benefit that could be derived from an additional etching step prior to the application of self-etch adhesives to enamel does not justify the risk of adversely affecting the bond strength to dentin. Further studies are required to evaluate the implications of additional desmineralization in the enamel and dentin and its effect on the bond strength when using self-etch adhesives.

In agreements with the results from previous studies ${ }^{1,13,19}$, our study showed increased bond strengths for the self-etching primer FL-Bond II 
than for the single step adhesive BeautiBond, except when bonding to un-etched enamel. The commercially available adhesives evaluated in this study are mildly acidic with a $\mathrm{pH}$ of arround 2.0. They feature an efficient self-etching chemistry containing phosphonic and carboxylic acid adhesive monomers that etch dental hard tissues, promoting wetting and monomer penetration into the surface ${ }^{15}$. In addition to a good micro-mechanical interlocking, the presence of phosphonic acid and carboxylic acid groups may contribute to the overall bond strengths due to the chemical adhesion to the calcium in the residual hydroxyapatite ${ }^{32,33}$.

In this study, a back-scattered electron mode was used to observe the failed bond interfaces. In this imaging mode, the contrast is principally determined by the average atomic number; therefore, identification of the different components (bonding agent, composite, and tooth structure) present at the interface is possible by the observation of the contrast in gray-scale images. Tooth structure (containing calcium and phosphorus), adhesive (primarily organic) and composite resin (containing inorganic fillers of high atomic number such as radiopacifiers) can readily be distinguished. In the system under investigation, the composite resin Z100 appears bright due to the zirconia filler particles, dentin presents an intermediate gray level due to the calcium, phosphorus and oxygen content, and the adhesive appears dark since its composition is primarily unfilled organic material. Similar to what has been reported previously ${ }^{21,29}$, our FE-SEM observations revealed that higher bond strength values were generally associated with mixed failures and lower bond strength values with adhesive failures. This was especially true for BeautiBond bonded to etched dentin, which revealed $100 \%$ adhesive failures while also showing the lowest bond strength of all groups $(18.3 \pm 6.7 \mathrm{MPa})$, and FL-Bond II bonded to nonetched dentin, which showed $100 \%$ mixed failures while also showing the highest bond strength of all groups (37.7 $\pm 3.2 \mathrm{MPa}$ ) (Table 3 ). Figure 1 provides representative images of the main failure modes observed. Figure 1A illustrates a mixed-type failure corresponding to the highest bond strength value (38.9 MPa) obtained from FL-Bond II group bonded to un-etched dentin. The image shows an area of cohesive failure in composite and dentin. Figure $1 \mathrm{~B}$ depicts an adhesive failure mode corresponding to the lowest bond strength value (7.3 MPa) obtained from the BeautiBond group bonded to etched dentin. The image shows spotted areas of adhesivecoated dentin and zones of dentin with resin tags protruding from the dentinal tubules.

\section{CONCLUSIONS}

Within the limitations of this in vitro study, we can conclude that an acid-etching step with $37.5 \%$ phosphoric acid prior to the application of the selfetch adhesives tested had a significant adverse effect on dentin while only providing significant improvement on the enamel bond strength for FL-Bond II, but not for BeautiBond. This finding suggests that the potential benefit that may be derived from an additional etching step with phosphoric acid does not justify the risk of adversely affecting the bond strength to dentin.

Overall, the two-step self-etch adhesive FLBond II demonstrated higher bond strengths than the one-step self-etch system BeautiBond, except when bonding to un-etched enamel. Future studies evaluating different adhesive systems under a variety of testing and storage conditions are required to validate the results of the present investigation.

\section{ACKNOWLEDGMENTS}

The author would like to thank Mr. Liang-Tso Tung for his participation in the preparation of the samples, Dr. Marc Campillo and Mr. Manthan Patel for their contribution with the statistical analysis, and Mr. Peter Bush for his assistance with the SEM imaging.

\section{REFERENCES}

1- Brackett WW, Ito S, Nishitani Y, Haisch LD, Pashley DH. The micro-tensile bond strength of self-etching adhesives to ground enamel. Oper Dent. 2006;31(3):332-7.

2- Brackett WW, Tay FR, Looney SW, Ito S, Haisch LD, Pashley $\mathrm{DH}$. Micro-tensile dentin and enamel bond strengths of recent self-etching resins. Oper Dent. 2008;33(1):89-95.

3- Carvalho RM, Chersoni S, Frankenberger R, Pashley DH, Prati C, Tay FR. A challenge to the conventional wisdom that simultaneous etching and resin infiltration always occurs in self-etch adhesives. Bio-materials. 2005;26(9):1035-42.

4- De Munck J, Vargas M, Iracki J, Van Landuyt K, Poitevin A, Lambrechts $P$, et al. One-day bonding effectiveness of new self-etch adhesives to bur-cut enamel and dentin. Oper Dent. 2005;30(1):39-49.

5- Erhardt MCG, Cavalcante LMA, Pimenta LAF. Influence of phosphoric acid pre-treatment on self-etching bond strengths. J Esthet Restor Dent. 2004;16(1):33-40.

6- Erickson RL, Barkmeier WW, Latta MA. The role of etching in bonding to enamel: a comparison of self-etching and etch-andrinse adhesive systems. Dent Mater. 2009;25(11):1459-67.

7- Gokce K, Aykor A, Ersoy M, Ozel E, Soyman M. Effect of phosphoric acid etching and self-etching primer application methods on dentinal shear bond strength. J Adhes Dent. 2008;10(5):345-9.

8- Hipolito VD, Alonso RC, Carrilho MR, Anauate Netto C, Sinhoreti MA, Goes MF. Micro-tensile bond strength test and failure analysis to assess bonding characteristics of different adhesion approaches to ground versus unground enamel. Braz Dent J. 2011;22(2):122-8. 
9- Ikeda M, Kurokawa H, Sunada N, Tamura $Y$, Takimoto M, Murayama $R$, et al. Influence of previous acid etching on dentin bond strength of self-etch adhesives. J Oral Sci. 2009;51(4):52734.

10- Inoue S, Vargas MA, Abe $Y$, Yoshida $Y$, Lambrechts $P$, Vanherle $G$, et al. Micro-tensile bond strength of eleven contemporary adhesives to dentin. J Adhes Dent. 2001;3(3):237-45.

11- Inoue S, Vargas MA, Abe Y, Yoshida Y, Lambrechts P, Vanherle $\mathrm{G}$, et al. Micro-tensile bond strength of eleven contemporary adhesives to enamel. Am J Dent. 2003;16(5):329-34.

12- King NM, Tay FR, Pashley DH, Hashimoto M, Ito S, Brackett WW, et al. Conversion of one-step to two-step self-etch adhesives for improved efficacy and extended application. Am J Dent. 2005;18(2):126-34.

13- Kiremitci A, Yalcin F, Gokalp S. Bonding to enamel and dentin using self-etching adhesive systems. Quintessence Int. 2004;35(5):367-70.

14- Marshall SJ, Bayne SC, Baier R, Tomsia AP, Marshall GW. A review of adhesion science. Dent Mater. 2010;26(2):e11-6.

15- Moszner N, Salz U, Zimmermann J. Chemical aspects of selfetching enamel-dentin adhesives: a systematic review. Dent Mater. 2005;21(10):895-910.

16- Pashley DH, Tay FR. Aggressiveness of contemporary selfetching adhesives: Part II: etching effects on unground enamel. Dent Mater. 2001;17(5):430-44.

17- Perdigão J. Dentin bonding as a function of dentin structure. Dent Clin North Am. 2002;46(2):277-301.

18- Perdigão J, Geraldeli S. Bonding characteristics of self-etching adhesives to intact versus prepared enamel. J Esthet Restor Dent. 2003;15(1):32-42.

19- Sadek FT, Goracci C, Cardoso PE, Tay FR, Ferrari M. Microtensile bond strength of current dentin adhesives measured immediately and 24 hours after application. J Adhes Dent. 2005; 7(4):297-302.

20- Sano H, Shono T, Takatsu T, Hosoda H. Microporous dentin zone beneath resin-impregnated layer. Oper Dent. 1994;19(2):59-64. 21- Taschner M, Nato F, Mazzoni A, Frankenberger R, Kramer N, Di Lenarda $R$, et al. Role of preliminary etching for one-step selfetch adhesives. Eur J Oral Sci. 2010;118(5):517-24.
22- Tay FR, Pashley DH. Aggressiveness of contemporary selfetching systems: I: Depth of penetration beyond dentinal smear layers. Dent Mater. 2001;17(4):296-308.

23- Tay FR, Pashley DH. Have dentin adhesives become too hydrophilic? J Can Dent Assoc. 2003;69(11):726-31.

24- Tay FR, Pashley DH. Water treeing--a potential mechanism for degradation of dentin adhesives. Am J Dent. 2003;16(1):6-12.

25- Tay FR, Pashley DH, King NM, Carvalho RM, Tsai J, Lai SC, et al. Aggressiveness of self-etch adhesives on unground enamel. Oper Dent. 2004;29(3):309-16.

26- Tay FR, Pashley DH, Suh BI, Carvalho RM, Itthagarun A. Single-step adhesives are permeable membranes. J Dent. 2002;30(7-8):371-82.

27- Tay FR, Sano H, Carvalho R, Pashley EL, Pashley DH. An ultrastructural study of the influence of acidity of self-etching primers and smear layer thickness on bonding to intact dentin. J Adhes Dent. 2000;2(2):83-98.

28- Torii Y, Itou K, Nishitani Y, Ishikawa K, Suzuki K. Effect of phosphoric acid etching prior to self-etching primer application on adhesion of composite resin to enamel and dentin. Am J Dent. 2002;15(5):305-8.

29- Van Landuyt KL, Kanumilli P, De Munck J, Peumans M, Lambrechts $P$, Van Meerbeek $B$. Bond strength of a mild selfetch adhesive with and without prior acid-etching. J Dent. 2006;34(1):77-85.

30- Van Landuyt KL, Snauwaert J, De Munck J, Peumans M, Yoshida $Y$, Poitevin A, et al. Systematic review of the chemical composition of contemporary dental adhesives. Bio-materials. 2007;28(26):3757-85.

31- Wang Y, Spencer P. Continuing etching of an all-in-one adhesive in wet dentin tubules. J Dent Res. 2005;84(4):350-4.

32- Yoshida Y, Nagakane K, Fukuda R, Nakayama Y, Okazaki M, Shintani $\mathrm{H}$, et al. Comparative study on adhesive performance of functional monomers. J Dent Res. 2004;83(6):454-8.

33- Yoshida Y, Van Meerbeek B, Nakayama Y, Snauwaert J, Hellemans L, Lambrechts $P$, et al. Evidence of chemical bonding at bio-material-hard tissue interfaces. J Dent Res. 2000;79(2):70914. 